\begin{tabular}{|l|l|}
\hline \multicolumn{2}{|c|}{ SNP Best-set Typesetter Ltd. } \\
\hline Journal Code: RATI & Proofreader: Elsie \\
\hline Article No.: 321 & Delivery Date: 1 March 2006 \\
\hline Page Extent: 15pp & \\
\hline
\end{tabular}


(C) 2006 The Author

Journal compilation @ 2006 Blackwell Publishing Ltd Ratio (new series) XIX 2 June 2006 0034-0006

\title{
EVANS'S ANTI-CARTESIAN ARGUMENT: A CRITICAL EVALUATION
}

\author{
Anne Newstead
}

\begin{abstract}
This paper evaluates the anti-Cartesian argument given by Evans in chapter seven of The Varieties of Reference. It focuses on Evans' claim that bodily awareness is a form of self-awareness. The apparent basis for this claim is the datum that sometimes judgements about one's position based on body sense are immune to errors of misidentification. However, Evans's argument suffers from a crucial ambiguity. Once disambiguated, it turns out that Evans's argument either begs the question against the Cartesian or fails to be plausible. Nonetheless, the argument is important for drawing our attention to the idea that bodily modes of awareness should be taken seriously as possible forms of self-awareness.
\end{abstract}

There is an on going debate between materialists and neoCartesians about self-awareness. Materialists about self-awareness, such as Evans (1982) and Cassam (1997), claim that selfawareness requires awareness of oneself as a body (or material object). ${ }^{1}$ This claim is supposed to follow from the idea that an adequate self-conception (one sufficient to differentiate oneself from others) must include the fact that one has a body. Neo-Cartesians, such as G. Strawson (1999), think that self-awareness does not require awareness of oneself as a body. ${ }^{2}$ Self-awareness is possible purely in virtue of awareness of oneself as a mental thing, just as Descartes thought. In this paper, I weigh in on behalf of the neo-Cartesian position by reconstructing Evans's anti-Cartesian argument and exposing its flaws. It is important to realize that the neo-Cartesian view is a view about the epistemic requirements for having first person thoughts: it is not directly a metaphysical view about the nature of the self or the 'I' that figures in

G. Evans, The Varieties of Reference, (Oxford: Clarendon Press, 1982); Q. Cassam, Self and World, (Oxford: Clarendon Press, 1997).

2 G. Strawson, Self and Body: Self, Body, and Experience', Proceedings of the Aristotelian Society, Supp. 73, 1999, pp. 307-332. 
'I' thoughts. Thus one can be a materialist metaphysically and a neo-Cartesian in one's theory of self-awareness.

Evans's argument does not attack the neo-Cartesian position directly. Rather, Evans starts with some apparently innocent observations about the nature of experience. Each person has experiences - such as feeling hot and sticky, knowing that one's legs are crossed, feeling a pain behind the knee - that are the experiences of a subject seemingly aware of her body. Evans's argument boils down to the claim that such experiences must be considered a kind of immediate awareness of one's self, suitable for grounding an adequate self-conception. It then follows that each person has a self-conception that includes the fact that she has a body. So materialism about self-awareness is supposed to follow just by taking our experiences at face value as a kind of self-awareness.

The crucial premise that Evans uses to conclude that such experiences constitute a kind of self-awareness, however, is not straightforward. Evans's crucial premise is this:

(*) Such bodily experiences give rise to judgements that are immune to error through misidentification [relative to the first person].

This premise is Evans's candidate for 'the greatest antidote to a Cartesian conception of the self'. He writes:

It is highly important that our 'I' Ideas are such that judgements controlled by certain ways of gaining knowledge of ourselves as physical and spatial things are immune to error through misidentification: that the bearing of the relevant information on 'I' thoughts rests on no argument, or identification, but is simply constitutive of our having an 'I' Idea. The fact that these ways of gaining knowledge of ourselves must enter into the informational component of a functional characterization of our 'I' Ideas - of what it is to think of oneself self-consciously - is the most powerful antidote to a Cartesian conception of the self. ${ }^{3}$

I will argue that the idea that our ways of gaining knowledge of ourselves as physical and spatial things cannot be 'simply constitutive of our having an 'I' Idea' without begging the question. Certainly intuitions about which judgements (made on which

3 Evans, Varieties of Reference, p. 220. 
bases) are immune to error through misidentification do not settle the issue. The crucial issue is whether the immunity of such judgements is relative to the first person, or to something else, such as 'my body'. This issue, however, cannot be settled by semantics and epistemology, but presupposes metaphysical commitments.

\section{Evans's anti-Cartesian argument}

Before laying out the anti-Cartesian argument in detail, several preliminary points must be made. First, Evans's argument assumes that we have some intuitive distinction between mental and bodily properties. The tendency of his argument is to undermine this distinction. However, dialectically the assumption is appropriate, since the Cartesian also assumes that we have a distinction between mental and bodily properties. Evans uses P. F. Strawson's distinction between $\mathrm{M}$ and $\mathrm{P}$ predicates, which pick out material (physical, bodily) properties and psychological (mental) properties respectively. ${ }^{4}$ Mental properties are properties that pertain to a subject with conscious experience. Bodily properties, on the other hand, belong to a subject that has a body. Quite possibly the class of mental and bodily properties overlap or even coincide. Nonetheless, we will assume for the purposes of the argument that we have some way of telling whether a property is mental or bodily in the first instance. Certainly a Cartesian will grant this assumption.

Second, we must fix the target of Evans's anti-Cartesian argument. Evans is sometimes broad and sometimes narrow in specifying his target. On the broad reading, a Cartesian is one who thinks that the self is purely mental (with no physical attributes). On the narrow reading, a Cartesian is one who falls for the claim that only self-ascriptions of such obviously mental states as thought and feeling on the basis of introspection can be immune to error through misidentification relative to the first person pronoun. Evans thinks that holding the narrow Cartesian view leads to adopting the broader Cartesian conception of the self:

Unfortunately, many philosophers give a quite mistaken impression that it is only our knowledge of our satisfaction of

4 P. F. Strawson, Individuals, (London: Methuen, 1958), p. 104. 
our mental properties which give rise to judgements exhibiting immunity to error through misidentification. This is tantamount to the claim that self-conscious thought rests only upon the knowledge we have of ourselves as mental or spiritual beings. And this in turn generates the unfortunate, and quite inaccurate, impression that in thinking of oneself selfconsciously, one is paradigmatically thinking about oneself as the bearer of mental properties, or as a mind - so that our ' $\mathrm{I}$ ' thoughts leave it open, as a possibility, that perhaps we are nothing but a mind. ${ }^{5}$

For this reason, Evans does not sharply distinguish between the broad and narrow readings of 'Cartesian'. This is a shame, because if he had, he might have seen that the narrow conception does not force one to adopt a broadly Cartesian metaphysical self-conception.

Third, as it plays a central role in Evans's argument, we should define the notion of immunity to error through misidentification. ${ }^{6}$ The following definition adequately captures the relevant notion. The idea is that there are some cases where to know that $\mathrm{F}$ is instantiated (in way w) is to know ipso facto that $a$ is $\mathrm{F}$ (in way w). In such a case, one cannot sensibly ask: 'Something is F, but is it $a$ ?'. The question is already closed, because it is only $a$ that one could access in way $\mathrm{w}$ and find to be F. In this case, the information about something being $\mathrm{F}$ comes in such a way that there can be no mistake or slippage about which individual is $\mathrm{F}$. When this is so, we say that the judgement ' $a$ is F', known in way w, is immune to error through misidentification relative to ' $a$ '.

Finally, we need some terminology for referring to judgements about our bodies made on the basis of bodily awareness or 'body sense'. 'Body sense' comprises a constellation of capacities for detecting one's own body's temperature, limb position, balance and movement. A particularly important component of body sense is proprioception, which provides immediate, noninferential knowledge of one's limbs positions relative to one another. Subjects can use 'body sense' to know 'from the inside'

Evans, Varieties of Reference, pp. 216-7.

Sydney Shoemaker, 'Self-Reference and Self-Awareness', Journal of Philosophy 65/19, 1968, pp. 555-67. Cf. Evans 1982, pp. 180-81. I ignore complications arising from Evans's modifications of Shoemaker's ideas (such as the notion of 'identification-freedom'), which are contrasted in J. Pryor 1999, 'Immunity to Errror Through Misidentification', Philosophical Topics 26, pp. 271-304. They are not relevant to assessing Evans's anti-Cartesian argument. 
how their bodies are configured. Evans's basic idea is that body sense constitutes a mode of self-awareness. Let's call judgements about one's body based on body sense 'B ascriptions'. Examples of B ascriptions include statements such as 'My legs are crossed', 'My palms are sweaty', and 'I am jumping up and down'.

Evans's anti-Cartesian argument then consists of these two premises and the conclusion:

(1) My B ascriptions (based on body sense) are immune to errors of misidentification relative to the first person pronoun.

(2) B ascriptions express a form of basic self-awareness.

(3) Therefore, my fundamental conception of myself is as of a bodily thing.

Premise (1) asserts that if someone makes a judgement about her body based on body sense, then she cannot be mistaken that she herself - the referent of 'I' - is the subject of that judgement. In premise (2), B ascriptions are said to express a basic kind of selfawareness, meaning that they convey immediate knowledge of one's self that is not based on or inferred from other judgements about oneself. The 'fundamental conception' of oneself is, among other things, the conception of oneself that figures in basic, foundational knowledge. ${ }^{7}$ Premise (3), the conclusion of the antiCartesian argument, is not the metaphysical conclusion that in fact we are bodily things; the conclusion is only that we conceive of ourselves as such. Consequently, the argument is not a knock down argument against Cartesian metaphysics. Rather, the argument is an invitation to the Cartesian to explain why our prima facie impression that we ourselves enjoy bodily sensations should not lead us to include the idea that we have bodies in our fundamental self-conception.

\section{Objections to the anti-Cartesian argument}

In this section, I will raise two serious objections to Evans's antiCartesian argument. Though the objections may look like tech-

7 Evans also uses the idea of the 'fundamental conception' of a thing to mean the concept of its essential nature, sufficient to differentiate it from all other things (Evans 1982, p. 107). Such a fundamental conception or Idea of oneself is not obviously basic for self-knowledge, since one may be differentiated from other objects by things of which one has no idea. Descartes' basic idea of himself as a thinker fails to be fundamental for Evans, since it fails to discriminate Descartes from other thinkers. 
nicalities or quibbles over the formulation of Evans's argument, they are not. The objections raise deep conceptual concerns about the assumptions at play in the argument.

My first objection is that premise (1) begs the question against Cartesians. Premise (1) states that B ascriptions are immune to error through misidentification relative to the first person pronoun. This begs the question as to whether the self - the referent of 'I' - is something that has bodily properties. To say that a judgement 'I am F' known in way w is immune to error through misidentification relative to ' $\mathrm{I}$ ' is to say that if one knows in way w that something is $\mathrm{F}$, one knows ipso facto in way $\mathrm{w}$ that one is oneself $\mathrm{F} .{ }^{8} \mathrm{In}$ other words, one knows oneself to be $\mathrm{F}$ - to be the kind of thing that can have the property F. So if F is a bodily property, then to know that ' $\mathrm{I}$ am F' is immune to error through misidentification relative to ' $\mathrm{I}$ ' is to know that it is appropriate to self-ascribe bodily properties. But of course, this is precisely what is at issue between the Cartesian and the materialist about self-consciousness (such as Evans). Cartesians do not think it is plausible to construe knowledge of one's body's properties as self-knowledge. But this must be granted to allow premise (1).

Let's be charitable. Perhaps Evans assumes that it is independently plausible to hold that B ascriptions are immune to error through misidentification relative to 'I'. What he says on the matter is this -

We have what might be described as a general capacity to perceive our own bodies, although this can be broken down into several distinguishable capacities: our proprioceptive sense, our sense of balance, of heat and cold, and of pressure. Each of these modes of perception appears to give rise to judgements which are immune to error through misidentification. None of the following utterances appear to make sense when the first component expresses knowledge gained in the appropriate way: "Someone's legs are crossed, but is it my legs that are crossed?"; "Someone is hot and sticky, but is it I who am hot and sticky?", "Someone is pushed, but is it I who am being

\footnotetext{
The reason for using 'knows' rather than 'believes' in the context of discussing immunity is that the judgement must be true and the awareness must be veridical in order to exclude a mistake of predication. Some mistakes of predication are so severe they make it impossible to assess the judgement as being a judgement about one rightly identified individual along with a mistake of predication.
} 
pushed?". ${ }^{9}$ There just does not appear to be a gap between the subject's having information (or appearing to have information), in the appropriate way, that the property of $\mathrm{F}$ is instantiated, and his having information (or appearing to have information) that he is F; for him to have, or appear to have, the information that the property is instantiated is just for it to appear to him that he is $\mathrm{F}^{10}$

In all but the first example, the judgement is clearly meant to be immune to errors of misidentification relative to 'I'. It's intuitive to think that when one feels pushed, one can make a first person judgement on this basis: I am feeling pushed. Here the reference of ' $\mathrm{I}$ ' is the whole person, with a mind and a body. A Cartesian can accept that persons have bodies - indeed Descartes himself held that a person is a 'substantial union' of a mind and a body. ${ }^{11}$ The key Cartesian position is that what one really is - the nature of one's self - is to be a thinker (a mind). So a Cartesian could accept that 'I am being pushed' is immune to error through misidentification relative to 'I', where 'I' refers to the whole person, body and mind together. A Cartesian could maintain this claim in conjunction with the belief that selves are distinct from persons, and unlike persons, selves do not have bodies. In order for the argument to lead to the conclusion that one's selfconception must include having a body, it is necessary for the referent of 'I' in 'I am being pushed' to be not one's person, but one's self. But of course a Cartesian does not grant that judgements about being pushed, for example, are about one's self: they are about one's person, or about one's body, but not about one's self.

My second objection to Evans's argument is that no specification of the kind of immunity attaching to B ascriptions is made

9 Of course as a referee rightly points out, there are contexts in which many of these utterances do make sense. These statements might perfectly describe the experience of patients suffering somatoparaphrenic delusions or anosognosic conditions. They might also describe the experience of healthy individuals undergoing illusions such as the rubber hand illusion discussed in M. Botvinick and J. Cohen, 'Rubber hands "feel" touch that eyes see', Nature 391, p. 756. Evans should have paid more attention to context of utterance here.

${ }_{10}$ Evans, Varieties of Reference, p. 224.

11 The primary source is Descartes' Letter to Elizabeth of 28 June 1643. For secondary literature on this point, see J. Cottingham, 'Descartes' Trialism', Mind XCIV, 374, April 1985, pp. 218-30; Paul Hoffman, 'The Unity of Descartes' Man', in The Philosophical Review XCV, no 3, July 1986, pp. 339-370. 
and once the specification is made, there is trouble. Premise (1) is ambiguous between

(1a) B ascriptions are relatively immune to error through misidentification (with respect to the first person pronoun).

and

(1b) B ascriptions are absolutely immune to error through misidentification (with respect to the first person pronoun)

Judgement-types are relatively immune to error through misidentification when some tokens of the judgement, made on some bases in some contexts, are immune to error through misidentification but other tokens of the same judgement-type are not immune to error through misidentification. Judgement-types are absolutely immune to error through misidentification when all tokens of that judgement type, in all contexts, are immune to error through misidentification. ${ }^{12}$ It matters which type of immunity is being claimed. If (1) is read as claiming relative immunity - as I think Evans intends - then (1a) does not support the inference to (2) or (3). Cartesians are likely to insist that (1) be read as claiming absolute immunity as in (1b) in order to support (2), and to claim that (1b) is false.

A Cartesian does not claim that B ascriptions are absolutely immune to error through misidentification - that is a privilege reserved for judgements about one's conscious mental states based on introspection. Cartesians think that B ascriptions are at best relatively immune to error through misidentification, and this is enough to render them unsuitable as a basis for self-knowledge. To say that 'I am F' (I am being pushed) is relatively immune to error through misidentification is to admit that in some circumstances, it may seem to me that I am being pushed, but in fact I am not being pushed. I may be having a tactile-kinaesthetic hallucination. In that case, since it is doubtful that I really am being pushed, I should not leap to the conclusion that "being something that can be pushed' must figure in my self-conception. All that

12 Sydney Shoemaker, 'Self-Reference and Self-Awareness', Journal of Philosophy 65 no. 19, 1968, pp. 555-67. 
must figure in a Cartesian's self-conception must be immune to such doubts.

The above disagreement arises because Evans and the Cartesian disagree about what constitutes a basic form of self-awareness, suitable as a foundation for self-knowledge. For Evans, basic selfawareness is merely self-awareness that gives rise to 'I' judgements that are immediately known (without inference). These judgements do not have to be incorrigible. Only mistakes of misidentification need to be excluded. For Cartesians, basic knowledge must not only be immediately known, but also incorrigible. Both mistakes of identification as well as mistakes of predication must be excluded from basic knowledge. Bodily awareness cannot give rise to such basic knowledge, because one's sensory awareness of the body may turn out to distort the body's true nature. Perhaps the problem is, as Evans thought, insufficient development of the idea that body sense provides one with a very good and quite special awareness of one's body. So a Cartesian will reject premise (2) of the argument, on the grounds that bodily awareness does not provide suitably basic knowledge.

\section{Cartesian replies}

In this section, I develop in detail a Cartesian response to Evans's anti-Cartesian argument, building on the objections raised previously. In particular, I demonstrate that a Cartesian could affirm that B ascriptions are relatively immune to error through misidentification - but with respect to 'my body' rather than 'I'. I also show how the Cartesian can use this strategy to parse ambiguous 'I' statements. I end by raising some objections to this procedure.

The Cartesian strategy requires saying that the reference of 'I' is dual, referring in one context to the subject's body and in another to the subject's mind. ${ }^{13} \mathrm{~A}$ theorist who holds that 'I' has a dual reference, and that sense is the manner in which an object is presented to a thinker, will have to accept that the sense of ' $\mathrm{I}$ ' will shift in accordance with its reference. Consequently such a

13 Cf. John Mackie, 'The Transcendental "I"', Philosophical Subjects: Essays presented to P. F. Strawson, ed. Z. van Straaten, (Oxford: Clarendon Press, 1980), pp. 48-61; Bill Brewer, 'Bodily Awareness and the Self', in José Luis Bermúdez, Antony Marcel, and Naomi Eilan, eds., (1995). The Body and the Self, (Cambridge, Mass.: MIT Press, 1998). 
theorist is committed to the claim that the sense of 'I' is equivocal or ambiguous. I shall call this position that of 'the Ambiguity Theorist'. The position comes in two varieties. First, there is the view that equivocation using 'I' is unavoidable; in some contexts, 'I' must refer to a human body, and in others, 'I' must refer to an immaterial ego. Second, there is the view that the ambiguity attaching to statements involving 'I' disappears when we give the proper paraphrase of those statements. 'I' properly speaking only refers to the immaterial ego, self, soul, or mind (whatever one wishes to call it). Statements in which a bodily property is attributed to the referent of 'I' are misleading and confused; properly interpreted, they attribute bodily properties to the body which is associated with a particular immaterial ego. It is this latter view that I have primarily in mind in discussing the view of the Ambiguity Theorist, and it is this position that it is natural for the Cartesian to occupy. ${ }^{14}$

In more detail, the position of the Ambiguity Theorist is this. One can accept both that ascription of mental properties to oneself and attribution of bodily properties to one's body are immune to error through misidentification (albeit with respect to different things), without accepting the Strawsonian concept of a person, of a self that is a bearer of both mental and bodily properties. It is open to the Cartesian dualist to claim that ' $\mathrm{I}$ ' is equivocal, so that self-ascriptions of mental predicates refer to $\mathrm{I}_{\mathrm{m}}$ (my mind), and apparent self-ascriptions of bodily predicates actually refer to $\mathrm{I}_{\mathrm{b}}$ (my body). Properly analysed, a statement like 'I am sitting down', or 'My legs are crossed', does not directly attribute a bodily property to the self; it claims that it is apparent to one's mind that the body with which is it is associated has the property of sitting down, or having its legs crossed. The use of 'I' in 'I am sitting down' goes proxy for 'my body' $\left(\mathrm{I}_{\mathrm{b}}\right)$. Similarly, in 'My legs are crossed', the phrase 'my legs' stands for 'the legs that belong to my body'. Thus the Cartesian can accept the immune to error through misidentification status of both

$$
\begin{gathered}
\text { ' } I_{m} \text { am in pain' } \\
\text { and ' } I_{b} \text { am sitting down'. }
\end{gathered}
$$

14 There is also the post-Cartesian view that 'I' sometimes refers to the psychophysical whole human being and sometimes refers just to the self. See, e.g., G. Strawson, 'The Self and SESMET', Journal of Consciousness Studies 6:4, April 1999, 99-135. However, consideration of this alternative is beyond the scope of this article. 
What kind of immunity attaches to each statement? ' $\mathrm{I}_{\mathrm{m}} \mathrm{am}$ in pain' is absolutely immune to error, since there is no bona fide way of finding out that one is in pain that renders the judgement subject to error. ' $\mathrm{I}_{\mathrm{b}}$ am sitting down', however, is relatively immune to error when it is made on the basis of bodily feeling. (If made on other bases, such as looking in the mirror, it is subject to error.). One might wonder how the Cartesian can claim that 'I am sitting down' is even relatively immune to error through misidentification with respect to ' $\mathrm{I}_{\mathrm{b}}$ '. His proposal might be that ' $\mathrm{I}_{\mathrm{b}}$ ' functions like the perceptual demonstrative term, 'this body', where use of this term depends on being in receipt of information from the body to which it refers. Thus, if the subject knows that the referent of 'this body' is sitting down, because he is in receipt of proprioceptive information coming from that body (in a normal way), then there is no gap between his knowledge that that body is sitting down, and his knowledge that his body is sitting down. ${ }^{15}$

So one can see how both statements about one's mental states and about one's body can be immune to error through misidentification with respect to ' $\mathrm{I}_{\mathrm{m}}$ ' and ' $\mathrm{I}_{\mathrm{b}}$ ' respectively. Nor does it follow from this proposal that $I_{m}$ and $I_{b}$ are identical. In this scheme, ' $I_{b}$ ' is elliptical for 'my body', and ' $I_{m}$ ' is synonymous with 'I, myself'. Since it is possible to rationally doubt whether 'I myself am identical with my body', it is clear that the senses of ' $\mathrm{I}_{\mathrm{m}}$ ' and ' $\mathrm{I}_{\mathrm{b}}$ ' are distinct. This point can be used to show that the Ambiguity Theorist cannot easily account for reasoning which trades on the identity between the bodily I-of-action and the mental I-of-perception.

It surely counts against the Ambiguity Theorist that we do often engage in reasoning that would only be valid given the univocity of 'I' ${ }^{16}$ Consider the following little arguments: 
Argument (A):

Argument (B):

I am $\mathrm{F}$

I am F.

I am G.

Whoever is $\mathrm{F}$, is $\mathrm{G}$.

Therefore, I am both $\mathrm{F}$ and $\mathrm{G}$.

Therefore, I am G.

Suppose that $\mathrm{F}$ is a mental predicate and that $\mathrm{G}$ is a bodily predicate. According to the Ambiguity Theorist, in Argument A, the first premise 'I am F' is elliptical for 'My mind is F'. The second premise 'I am G' is either elliptical for 'My body is G', or it is simply false. Suppose that the second premise is true and properly read as 'My body is G'. The conclusion, 'I am both F and G', could say any of the following:

i) My mind is F and my body is $\mathrm{G}$

ii) My mind is $F$ and my mind is $G$

iii) My body is $\mathrm{F}$ and my body is $\mathrm{G}$

Options ii) and iii) are unacceptable to the Ambiguity Theorist, because he assumes that we cannot ascribe bodily properties to mental things, or mental properties to bodily things. Now suppose 'I am F' and 'My body is G' are necessary truths on the Cartesian picture, such as 'I am thinking thing' and 'My body is material'. On options ii) and iii), and this interpretation of the premises, Argument A cannot come out as valid. So the Ambiguity Theorist is left with option i), which advances him no further than a repetition of the premises. Now he has an argument that is valid but utterly uninformative. On the face of it, though, Argument A appears both valid and to advance our knowledge. We are supposed to infer from the premises that properties $\mathrm{F}$ and $\mathrm{G}$ are coinstantiated in me. But the Ambiguity Theorist cannot account for this plausible analysis of Argument A.

Argument B is also objectionable to the Ambiguity Theorist. He analyses Argument B as follows:

i) My mind is $\mathrm{F}$

ii) Any mind that is $\mathrm{F}$ is also G.

iii) Therefore, my mind is $G$.

Now the problem is not that the argument appears invalid; it is that the second premise attributes a bodily property to a mind, and the position of the Cartesian-cum-Ambiguity Theorist is that this cannot happen. So the argument is unsound for him. 
What might the Cartesian say in response? One possibility is to maintain that the Cartesian-cum-Ambiguity Theorist can acknowledge the validity of the inferences across mental and bodily domains, but has to add extra steps or qualifications to the argument in order to make it valid. ${ }^{17}$ For example, the Cartesian might recast Argument B as follows:

i) My mind is $\mathrm{F}$

ii) Any mind that is $\mathrm{F}$ is related by the ownership condition to a body that is $\mathrm{G}$.

iii) My mind is related by the ownership condition to a body that is $\mathrm{G}$.

Similarly, the Cartesian could argue that Argument A should read:

i) My mind is $\mathrm{F}$.

ii) My body is $\mathrm{G}$.

iii) Whenever my body is $G$, it seems to me that my body is $G$.

iv) Whenever my mind is $\mathrm{F}$, it seems to me that my mind is $\mathrm{F}$.

v) It seems to me that my mind is $F$ and that my body is $G$.

Suitably recast, the Cartesian can make arguments A and B come out valid while respecting his view that bodily properties and mental properties must be attributed to distinct substances. The arguments do not have the simplicity of the original arguments, and in fact deliver conclusions that are weaker than the conclusions of the original arguments. But they are valid, and so the objection that the Ambiguity Theorist cannot account for the validity of arguments involving inferences across mental and bodily domains is not decisive.

To summarize, I have shown that the Ambiguity View has difficulty in accounting for the validity of first person reasoning that trades on the identity of 'I' across mental and bodily predications. This difficulty is not insuperable for the position. I suspect that there will always be some move open to the Cartesian willing to go far enough to defend the Ambiguity View. The Ambiguity View offers the Cartesian a way of affirming both dualism and that certain bodily self-ascriptions are immune to error when made on the appropriate basis. 


\section{Conclusions}

I have argued that Evans's anti-Cartesian argument does not succeed. The argument either begs the question against the Cartesian - by assuming that there is such a thing as a bodily self-ascription, or the argument simply fails to have a purchase on the Cartesian position. If Cartesianism fails, it is not because of the observation that certain kinds of bodily self-ascriptions are immune to error through misidentification. For as we have seen, the Cartesian can accommodate this claim under some interpretations.

We should not be surprised at this result, since it illustrates the point that one cannot draw a metaphysical conclusion immediately from the fact that certain claims are immune to error through misidentification. For all but a handful of predicates $\phi$, the fact that ' $I$ am $\phi$ ' is immune to error through misidentification is compatible with the falsity of the claim that I am $\phi$, for there may be an error of predication. This is not to say that one cannot work one's way to a metaphysical conclusion, but there have to be additional steps that Evans doesn't consider. For example, one can argue along the following lines:

(4) 'I am $\phi$ ' is immune to error through misidentification with respect to 'I'.

(5) 'I am $\phi$ ' is true.

(6) $\phi$ expresses a bodily property.

(7) Anything that has a bodily property has a body.

(8) So, the referent of 'I' in 'I am $\phi$ ' has a body. [from, 4, 5, $6,7]$.

Here the claim that will be disputed by the Cartesian is the conjunction of (5) and (6); the Cartesian in the guise of the Ambiguity Theorist, for example, will hold that if $\phi$ expresses a bodily property, then 'I am $\phi$ ' is elliptical for 'My body is $\phi$ ', where 'my body' and 'I' are not co-referential. In this case, the conclusion (8) is blocked, and all that follows is the unsurprising claim, acceptable to Cartesians and materialists alike, that the referent of 'my body' is something that has a body. In declining to interpret 'I am $\phi$ ' in a straightforward sense when ' $\phi$ ' is a bodily predicate, the Cartesian is allowing his metaphysical views to shape his semantics. It can be argued that the roundabout interpretation to which the Cartesian resorts is a disadvantage of his position. 
But it should be clear that the mere discovery that certain bodily self-ascriptions are immune to error through misidentification with respect to the first person pronoun does not, by itself, provide an antidote to Cartesianism. ${ }^{18}$

School of philosophy

University of New South Wales

Sydney NSW 2052

a.newstead@unsw.edu.au

18 I would like to thank Bill Brewer, John Campbell, and Quassim Cassam for comments on an earlier draft. I would also like to thank an anonymous referee at Ratio for comments. Though the writing of this paper was done in Australia, the ideas were conceived at Wolfson College, Oxford. 